\section{Endostatin for fibrosis}

\section{By Lauren Martz, Staff Writer}

University of Pittsburgh School of Medicine researchers have shown that a compound derived from endostatin prevented and reversed organ fibrosis in mice. ${ }^{1}$ The findings may suggest a new use for endostatin, which is approved in China as an antiangiogenic agent to treat cancer.

Endostatin is a fragment of the C-terminus of collagen XVIII. In 1996, EntreMed Inc. began developing endostatin, and preclinical results showed the fragment inhibited endothelial cell proliferation and tumor growth. ${ }^{2}$

EntreMed took the compound into the clinic in 1999 but in 2004 discontinued the endostatin program during a Phase II trial due to their refocusing on small molecule cancer therapeutics. In 2004, EntreMed transferred rights to the peptide back to the original owner-Boston Children's Hospital-and to Alchemgen Therapeutics Inc.

Endostatin is approved in China, where Simcere Pharmaceutical Group markets a recombinant form of the peptide called Endostar to treat non-small cell lung cancer (NSCLC).

EntreMed declined to comment, and Simcere and Boston Children's Hospital did not respond to interview requests.

Now, a University of Pittsburgh team led by Carol Feghali-Bostwick has tested whether increasing levels of endostatin has a protective role in organ fibrosis. Feghali-Bostwick is associate professor of medicine and pathology.

The researchers built on previous papers from other groups that showed elevated levels of endostatin in the serum and bronchoalveolar lavage fluid of patients with idiopathic pulmonary fibrosis (IPF) or systemic sclerosis (SSc)-associated pulmonary fibrosis. ${ }^{3,4}$ However, in those studies it was unclear whether the high levels promoted fibrosis or served as a protective response against disease progression.

To determine whether endostatin was helping or aggravating fibrosis, Feghali-Bostwick's group used an ex vivo model of human skin fibrosis. The researchers found that an intradermal injection of recombinant human endostatin prevented transforming growth factor- $\beta$ (TGFB; TGF $\beta$ )-mediated increases in dermal thickness without affecting the thickness of normal skin.

Next, the team generated peptide fragments of endostatin to identify the region responsible for the antifibrotic effects and found that a section from endostatin's C-terminus had efficacy similar to that for the fulllength peptide in the ex vivo model. They modified the fragment to improve its serum stability and resistance to proteolytic degradation, calling the final peptide E4.

Feghali-Bostwick told SciBX that E4 has multiple advantages over the parent endostatin molecule, including stability and ease of manufacturing.

"What makes our peptide different is that it is shorter and less expensive to manufacture, and it has a modification at its carboxy terminal end that protects it from degradation and makes it more stable," she said.

In the ex vivo human skin model, injection of $\mathrm{E} 4$ during profibrotic TGF $\beta$ administration prevented skin thickening. When E4 was given two days after TGF $\beta$, the peptide fragment decreased skin thickening compared with vehicle control.

In mouse models of dermal fibrosis induced by either TGF $\beta$ or the chemotherapeutic bleomycin, E4 prevented fibrosis or decreased fibrosis compared with vehicle control. Similarly, in mouse models of bleomycin-induced pulmonary fibrosis, intratracheal or intraperitoneal administration of $\mathrm{E} 4$ prevented or reversed fibrosis.

Data were published in Science Translational Medicine.

"[E4] seems to exert antifibrotic activity even when given after fibrosis has started, whereas most other compounds and molecules are tested for their ability to prevent fibrosis," Feghali-Bostwick told SciBX. "The next steps are to conduct pharmacokinetic and toxicology studies."

Fibrosis company Actelion Ltd. said additional studies need to flesh out the precise mechanism by which E4 works. In addition, the company cautioned that animal models of fibrosis typically are acute, whereas human fibrosis is chronic and progressive.

Actelion's Macitentan, a tissue-targeting endothelin receptor antagonist, is in Phase II testing to treat pulmonary fibrosis. The compound is in Phase III testing to treat essential hypertension, pulmonary arterial hypertension (PAH) and pulmonary hypertension $(\mathrm{PH})$.

But Feghali-Bostwick noted that her group has "tested the peptide in human skin to show that it would be effective in human tissues, whereas other molecules were tested in animal models only, usually in mice, and then failed in the clinic when used in humans."

The university has filed a patent application covering E4 and is interested in partnering with a company to explore sponsored research, optioning and licensing opportunities.

Martz, L. SciBX 5(26); doi:10.1038/scibx.2012.671

Published online June 28, 2012

\section{REFERENCES}

1. Yamaguchi, Y. et al. Sci. Transl. Med.; published online May 30 2012; doi:10.1126/scitransImed.3003421 


\section{ANALYSIS}

Contact: Carol A. Feghali-Bostwick, University of Pittsburgh School of Medicine, Pittsburgh, Pa.

e-mail: feghca@upmc.edu or feghali2@pitt.edu

Contact: Yukie Yamaguchi, same affiliation as above

e-mail: yui1783@yahoo.co.jp

Contact: Adriana T. Larregina, same affiliation as above e-mail: adrianal@pitt.edu

2. BioCentury 6(42), A4; May 11, 1998

3. Sumi, M. et al. J. Clin. Lab. Anal. 19, 146-149 (2005)

\section{TARGETS \& MECHANISMS}

4. Hebbar, M. et al. Arthritis Rheum. 43, 889-893 (2000)

COMPANIES AND INSTITUTIONS MENTIONED

Actelion Ltd. (SIX:ATLN), Allschwil, Switzerland

Alchemgen Therapeutics Inc., Houston, Texas

Boston Children's Hospital, Boston, Mass.

EntreMed Inc. (NASDAQ:ENMD), Rockville, Md.

Simcere Pharmaceutical Group (NYSE:SCR), Nanjing, China

University of Pittsburgh School of Medicine, Pittsburgh, Pa. 